\title{
A HOLISTIC VIEW OF SCHISTOSOMIASIS AND SNAIL CONTROL
}

\section{J. D. THOMAS}

\author{
School of Biological Sciences, University of Sussex, Falmer, Brighton BN1 9QG, UK
}

The elucidation of the life cycle of the three major human schistosomes in Japan and Egypt from 1910-1920 (Jordan \& Webbe, 1982; Jordan, 1985) has made it possible to identify the components which might be perturbed to reduce or prevent transmission. These perturbations aim to reduce the probability of survival of various stages of the parasite: (i) The adult parasite (by using drugs and vaccines), (ii) the miracidia (by reducing contamination of water contact sites), the cercariae (by reducing contact time with infected water, (iv) the snail host and hence the larval stages of the parasite (by chemical or bioengineering means). Opinions regarding which of these strategies might be most appropriate for the control of schistosomiasis have changed over the course of time. In the earlier campaigns more emphasis was given to control of the molluscan hosts in order to interrupt transmission. However, now that safer, orally administered drugs are available, emphasis has shifted to the control of morbid. ity or disease, by intermittent drug prophylaxis (Warren, 1987).

This author also considers that genetic engineering holds the promise of producing protective antigens which will induce a significant degree of immunity. He goes on to suggest that when a vaccine becomes available the opportunity to control disease, and to a certain extent infections, with a combination of vaccines and drug prophylaxis, will become a reality. However, arguments are given below which suggest that these views are over optimistic and that the pendulum has swung too far towards chemotherapy and vaccines. A more balanced holistic approach to the problem, which is better suited to the needs and resource base of the developing countries, is therefore needed.

\section{AN EVALUATION OF EXISTING CONTROL STRATEGIES}

Prevention of contamination - There appears to be no good quantitative evidence on the effects of reducing or preventing contamination by the provision of latrines. Unfortunately, the possible effect of this perturbation was not investigated in the important series of experiments undertaken in St. Lucia (Jordan, 1985) possibly because the Macdonald model (1965) predicted that reduction in contamination would have practically no effect on the transmission rate. However, as stated by Hairston (1971) this result was attributable to the fact that in his basic model Macdonald as. sumed that a large proportion of the excreta would enter the water. This resulted in a very high percentage of the snails $(>98 \%)$ becoming infected. As a consequence the levels of reduction imposed in Macdonald's model had no effect on the level of infection. Many claims have also been made that the provision of latrines had little or no effect on the transmission rate in the field, but as stated by Hairston (1971), this apparent failure can be attributed to the latrines being little utilized because of bad design or the unwillingness of people to depart from the old conventions.

Reduction of water contact by provision of clean water - The results from St. Lucia (Fig. 1) show that this perturbation does result in a marked reduction in the age prevalence curve. However measures such as the provision of piped water supply can be counter-productive if no allowance is made for surface drainage. This problem is well illustrated in Pontezinha in N.E. Brazil. Here each house in this township was provided with a piped water supply (Plate 1) as a result of the recent Special Programme for Schistosomiasis Control (PECE) (Machado, 1982 ) and previous campaigns. However, as no account was taken of surface drainage, the runoff from a large number of taps has generated small streams which run in the streets, creating gulleys and swampy areas in banana plantations (Plate 2). During the wet season, flooding results in the snails being carried into a variety of temporary habitats (e. g. roadways used by bare-footed children) and even into human habitations. As these streams are continually being contaminated with the faecal matter deposited from adjacent houses and by children, who use the banana plantations as defaecation sites, it is easy to see how transmission can take place. This failure to implement fully control measures helps to explain why expensive national programmes, such as PECE, have not been completely successful. 


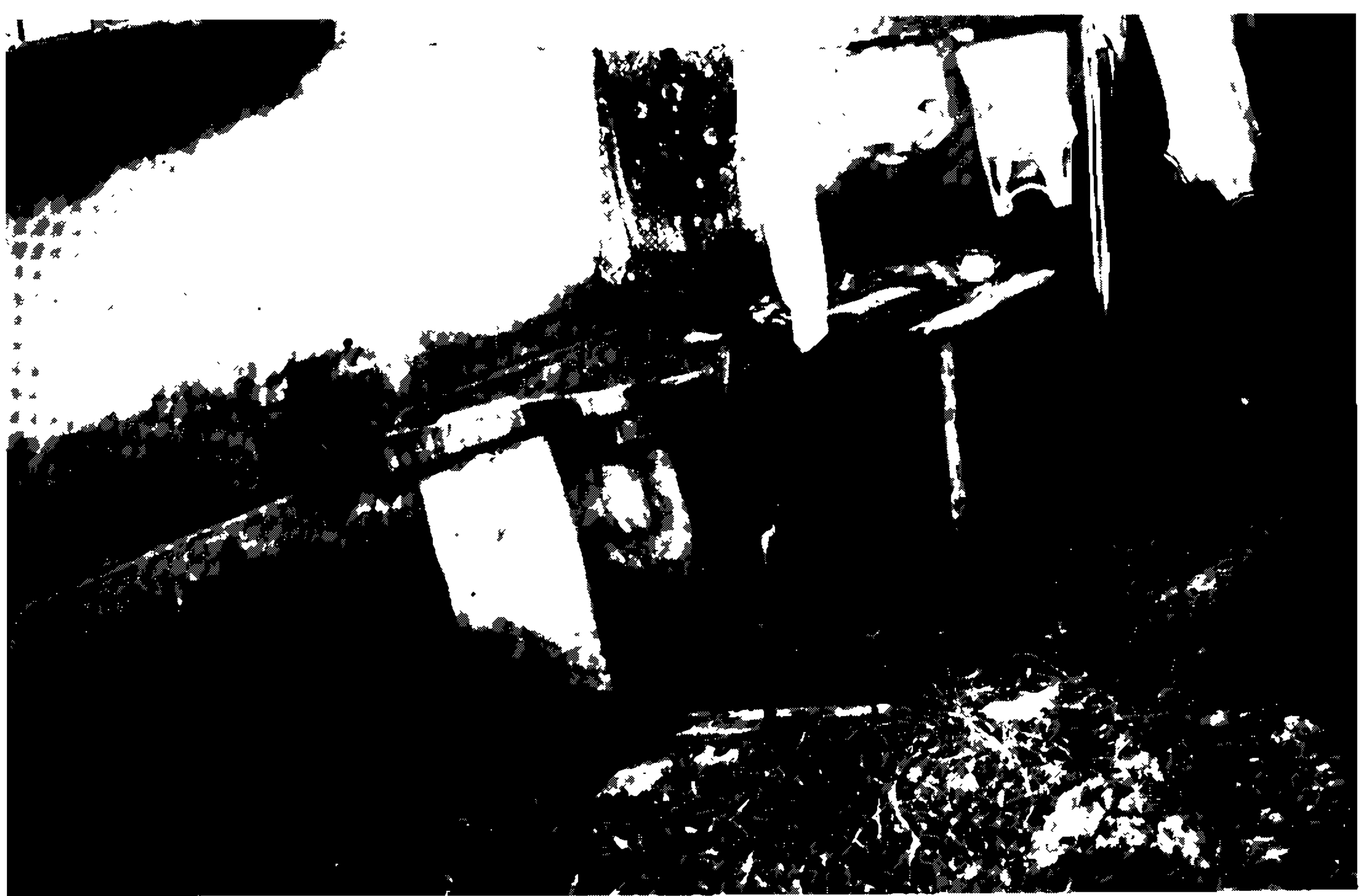

Plate 1: an example of one of the water taps placed outside each house in Pontezinha, N. E. Brazil as a component of the schistosomiasis control programme. Note that in the absence of surface drainage the run-off from these taps generates small pools and gullies which serve as snail habitats.

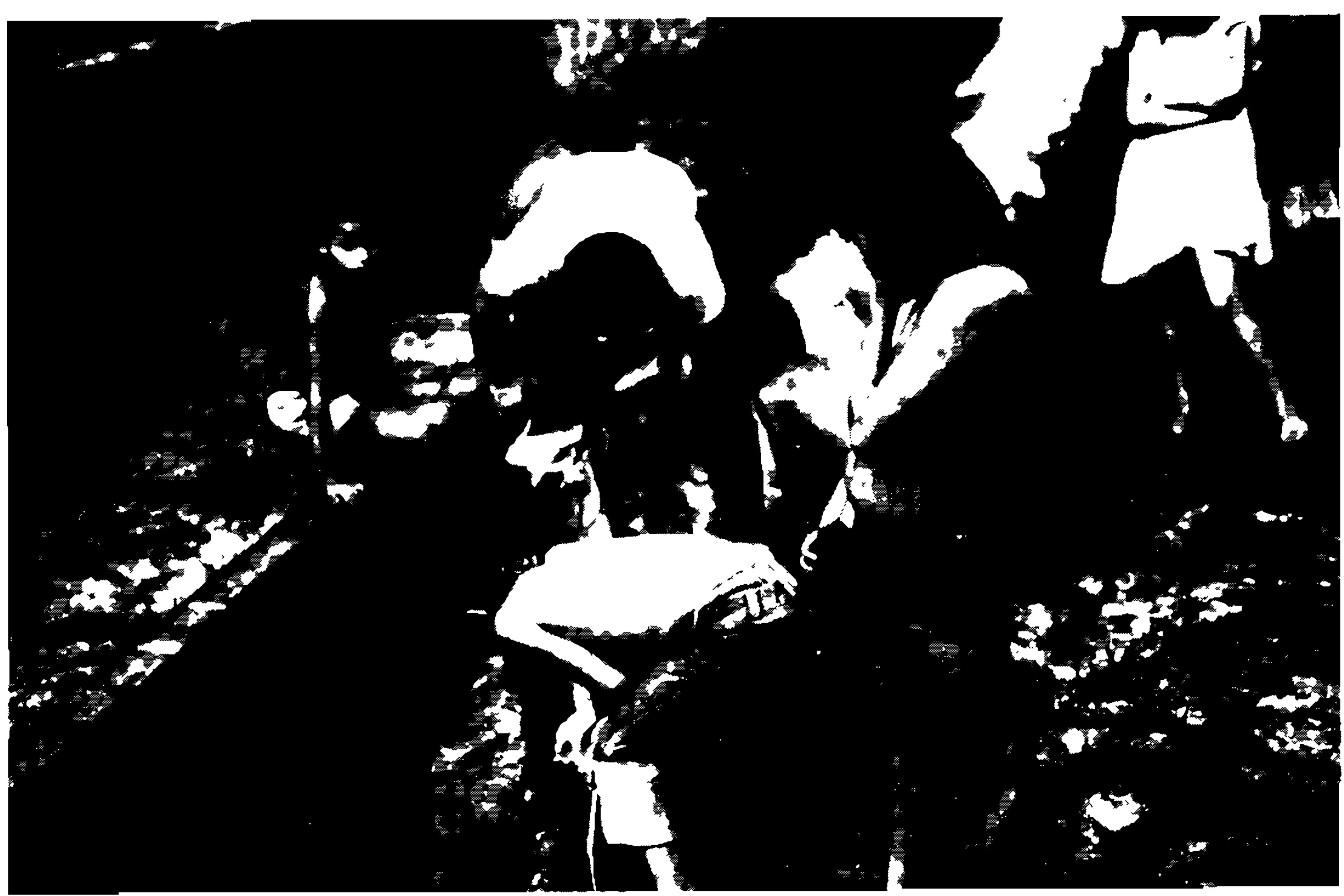

Plate 2: gullies formed in the streets in Pontezinha by run-off from water taps. Biomphalaria glabrata living in these become infected as a result of contamination of faecal matter deposited from adjacent houses or by children in banana plantations. During the wet season the snails may be carried into houses. 


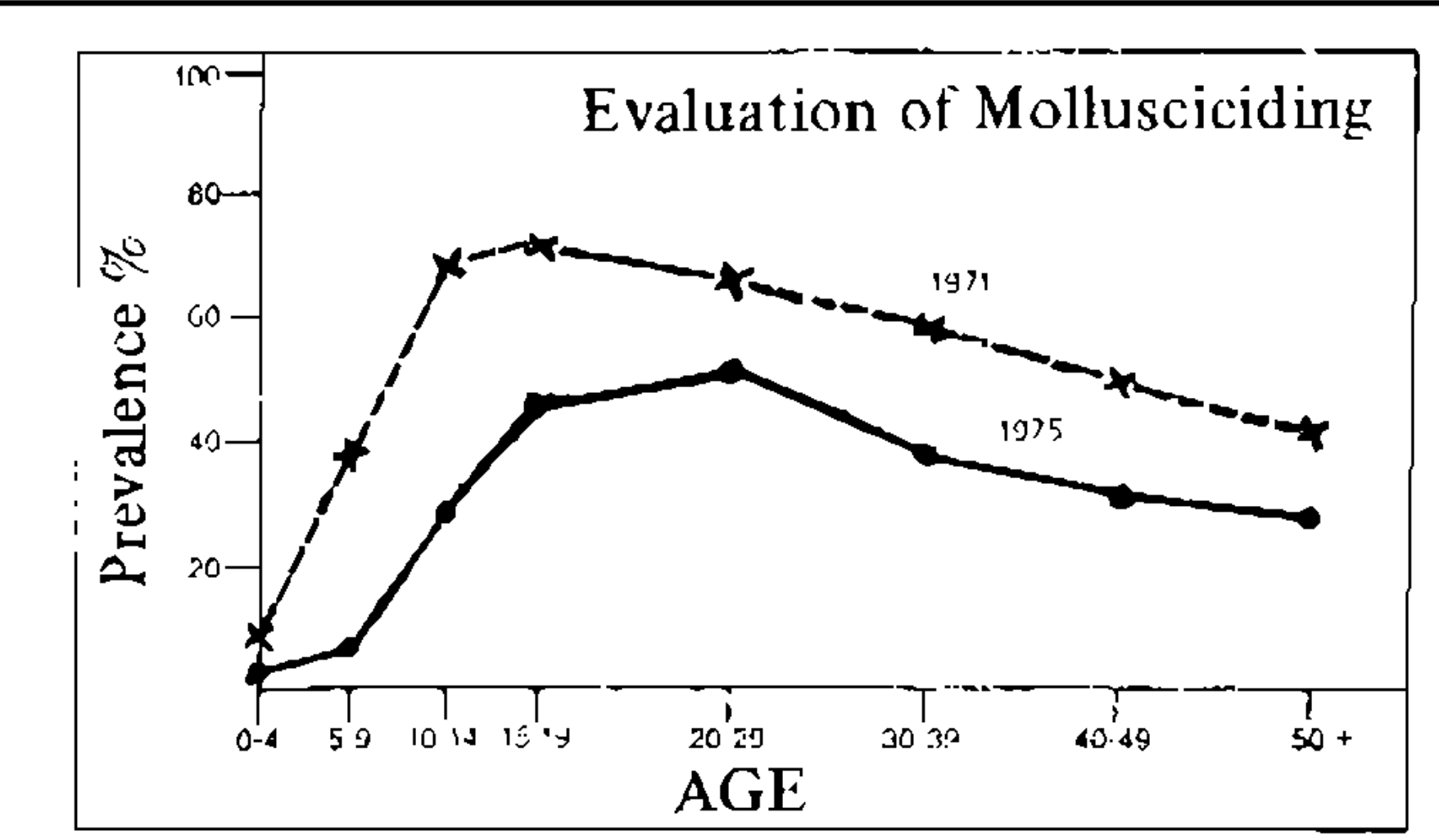

Graph shows drop in prevalence, by age group, of $S$. Mansoni infection in an area of cul-de-sac, St Lucia, before mollusciciding, and four years after the campaign was completed.

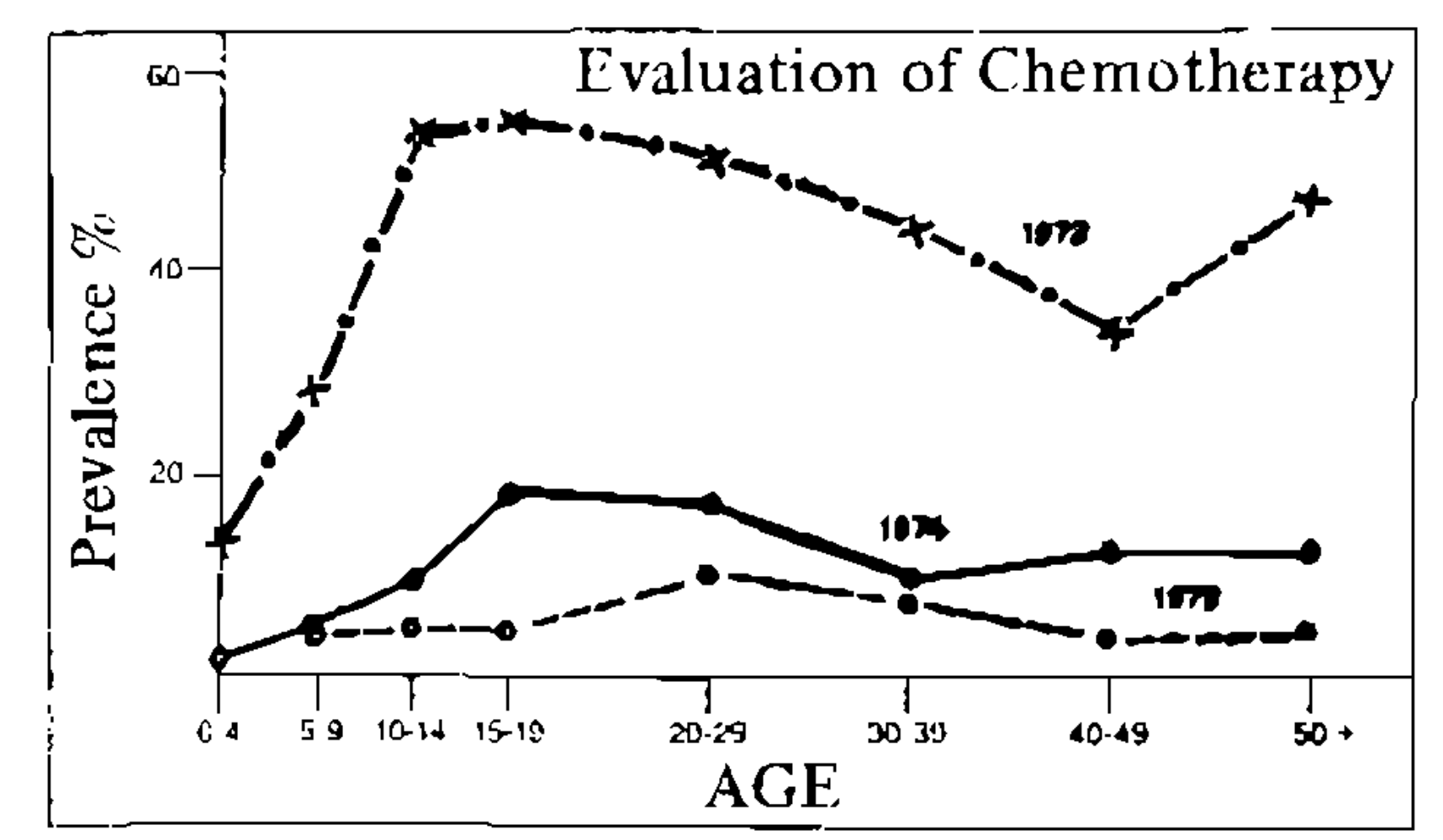

Prevalence of infection dropped markedly in marquis valley within a year after people were given injections of hycanthone. Final chemotherapy campaign in 1975 to cover remaining infected cases brought the rates even lower.

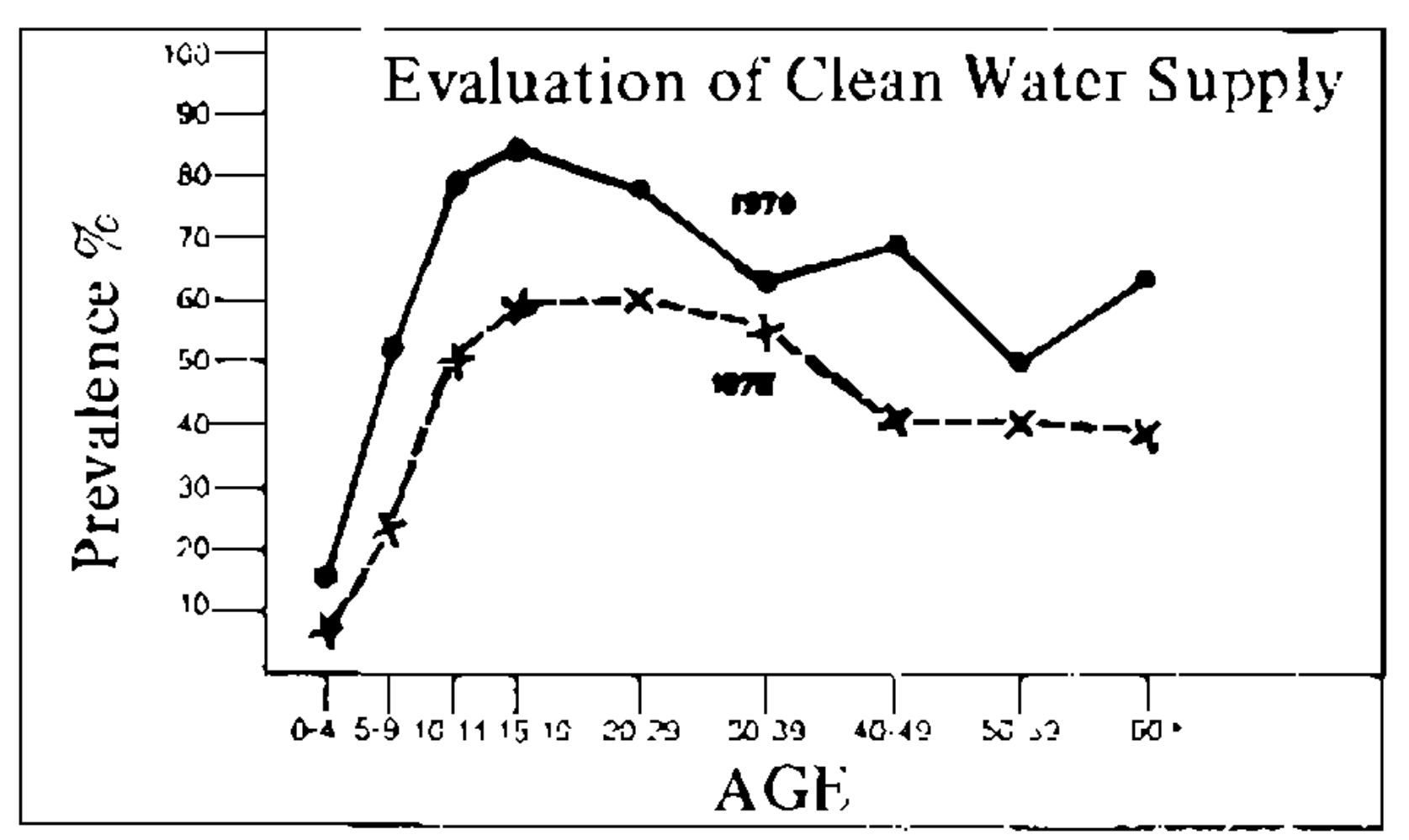

Five years after an experimental water system was installed in riche fond valley, St. Lucia. in 1970. the prevalence of infection was down for each age group

Fig. 1: the results obtained from chemotherapy, mollusciciding and reducing water contact in the St Lucia experiments.

Chemotherapy - Fig. 1 shows that although the application of chemotherapy in St. Lucia over a two-year period resulted in a marked decrease in prevalence rates, it did not result in achievement of the break point. There are also many problems associated with the use of chemotherapy.

\section{Problems associated with chemotherapy.}

1. High costs, e. g. Praziquantel costs US\$ 4 per treatment, which is $16.7 \%$ of the annual budget for Zimbabwe.
2. Difficulty of treating everyone, due to the high level of mobility of the human population and resistance to treatment.

3. People become reinfected, and repeated treatment is needed.

4. Resistance develops (see Bruce, 1987; Mott, 1987b).

5. Side effects, even with now relatively safe drugs.

Vaccine development - Vaccine development is still at the experimental stage. As there are very considerable difficulties to be overcome, it may be a long time, if ever, before an effective vaccine is developed.

\section{Problems associated with the development of a} vaccine:

1. The parasite has evolved within the host's immune system, and not surprisingly has evolved several sophisticated strategies to neutralise or escape the host's immune response (Damian, 1987; Dunne et al., 1987).

2. It has been found that children are highly susceptible to reinfection after chemotherapeutic cure (Dunne et al., 1987). As there is no acquired long term immunity, at least in children. the immunologist will have to do better than nature has been able to accomplish by natural selection. This seems improbabic.

3. The parasites are likely to be variable genetically, both in space and time.

4. High costs and logistic problems in implementation even if a vaccine were to be developed.

Snail control - These is a great deal of evidence from field experiments carried out in St. Lucia (Fig. 1) (Jordan, 1985 and elsewhere WHO, 1980; Jordan \& Webbe, 1982) that a decline in snail numbers is followed by a fall in prevalence rates although never to zero.

The general conclusion from application of control measures -- As predicted from the Macdonald (1965) model none of the control measures on its own was able to achieve the breakpoint. As a result there is a general con. sensus (Hoffman et al.. 1982) that an in tegrated approach of which snail control should be a part, is needed.

Particular attention to snail control needs to be given for the following reasons: 
a) Even if latrines and piped water supplies were provided the following categories of people would be at risk: - fishermen and farmers by the nature of their work and children because of their compulsive need to use water for recreational purposes. There is strong evidence that the latter category is mainly responsible for schistosomiasis transmission (Jordan, 1972; Worthington, 1979).

b) It is very difficult to prevent contamination of such water bodies by people and other mammalian hosts (e. g. rodents, primates and domestic animals) who act as reservoir hosts (Machado et al., 1987; Modena et al., 1987; Jordan \& Webbe, 1982).

c) The alternative to preventive medicine involving snail control in natural and man-made water bodies would be to use intermittent chemotherapy indefinitely to reduce morbidity. For the reasons given above, this is unacceptable.

\section{Difficulties with snail control}

a) The molluscan hosts tend to flourish in man-made aquatic habitats (Fig. 2) for many reasons including the reduced flow rates in lotic habitats, increase in amount of depositing sediment, increased levels of organic matter, absence of animals which might have been natural regulators and increased abundance of macrophytes with which snails tend to be strongly associated (Thomas, 1987).

b) They have evolved behavioural, physiological, and biochemical mechanisms which allow them to survive natural challenges, such as anoxia, toxic chemicals and desiccation, for short periods at least.

c) The high life-expectancy of the adult parasites (about 2-3 years in Schistosoma haematobium and 5-10 years in $S$. mansoni) would mean that snails would be continually infected from this reservoir unless chemotherapy was also used (Jordan \& Webbe, 1982).

d) It has been claimed that in areas of high endemicity the breakpoint would be close to snail eradication (Jordan \& Webbe, 1982; Jordan, 1985).

e) High dispersionary powers of both snail and human hosts.

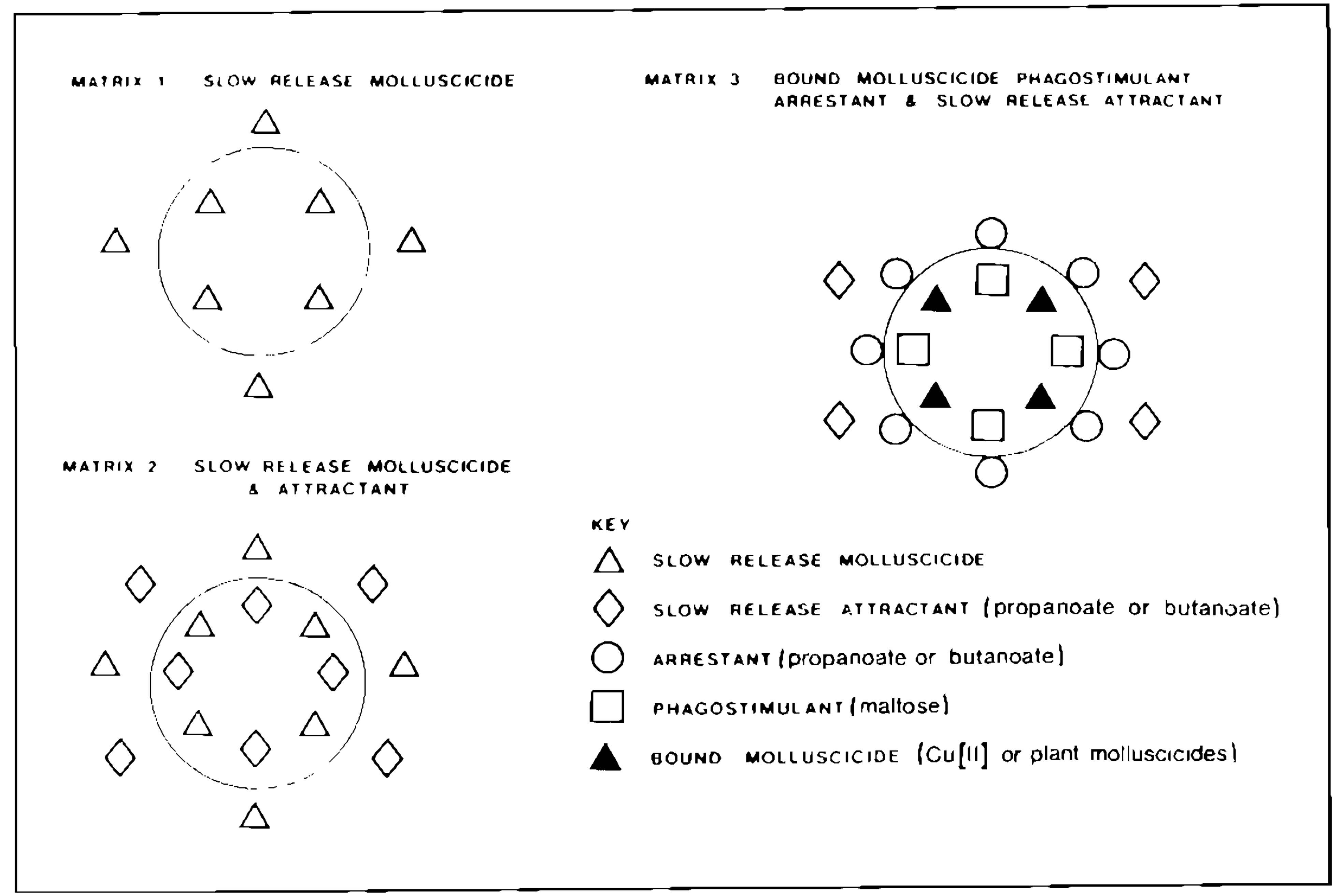

Fig. 2: diagramatic representation of the population growth patterns that one might expect for Biomphalaria glabrata in "primitive habitats" untouched by modern man and also in lotic and lentic habitats influenced by the activites of man today. 
In vicw of these difficulties the ideal snail control measures should be aimed at excluding the snail hosts, or keeping them at a very low level indefinitely.

\section{Methods of snail control}

a) lise of synthetic molluscicides - At present this is the only effective method of reducing snail numbers drastically in the short term. However, there are considerable problems associated with their use.

\section{Problems associated with the use of synthetic} molluscicides

1. High costs, often resulting in foreign exchange problems.

2. Lack of specificity, may harm man, if applied to potable water supplies (which are very widespread in the developing countries). domestic animals, fish and other organisms which may act as biological control agents.

3. Strong environmental resistance to molluscicide reaching target organisms.

4. Low profit margins and high costs of development have prevented industrial firms from trying to produce now products. The only one currently available is Bayluscide.

b) Use of natural plant molluscicides - A very large number of plants have been found to possess molluscicidal properties (McCullough \& Mott, 1983: Mott, 1987a). These include Phytolacca dodecandra (Endod), (Lemma, 1983). Callendula micrantha (Shoeb \& ElChany Refahy, 1984), Alternanthera sessilis (Thomas, 1987). Although their use might overcome the problem of high costs, they suffer from problem (2) and (3) listed in the examples of Density legislatin' measures below. The re are also other difficulties associated with their use. For example. the amount of molluscicide in the crude plant extract is often very variable and the extract may also contain other chemicals with toxic, mutagenic and carcinogenic propcrties to man or his domestic animals. As a result cnvironmental screcning becomes a very difficull problem.

c) Use of controlled release formulations $\left(C R F_{S}\right)$ to produce "environmental antibodies" - One of the first generation CRF systems consisting of soluble glasses which release copper at the required rate (Fig. 3) holds some promise (Drake \& Grallam, 1976; Chandiwana \& Ndamba, 1987). However, this system suffers from the difficulty that the toxic form. Cu (11), is rapidly inactivated by organic and inorganic ligands in snail-frequented waters which are usually rich in bases. organic matter and clays.

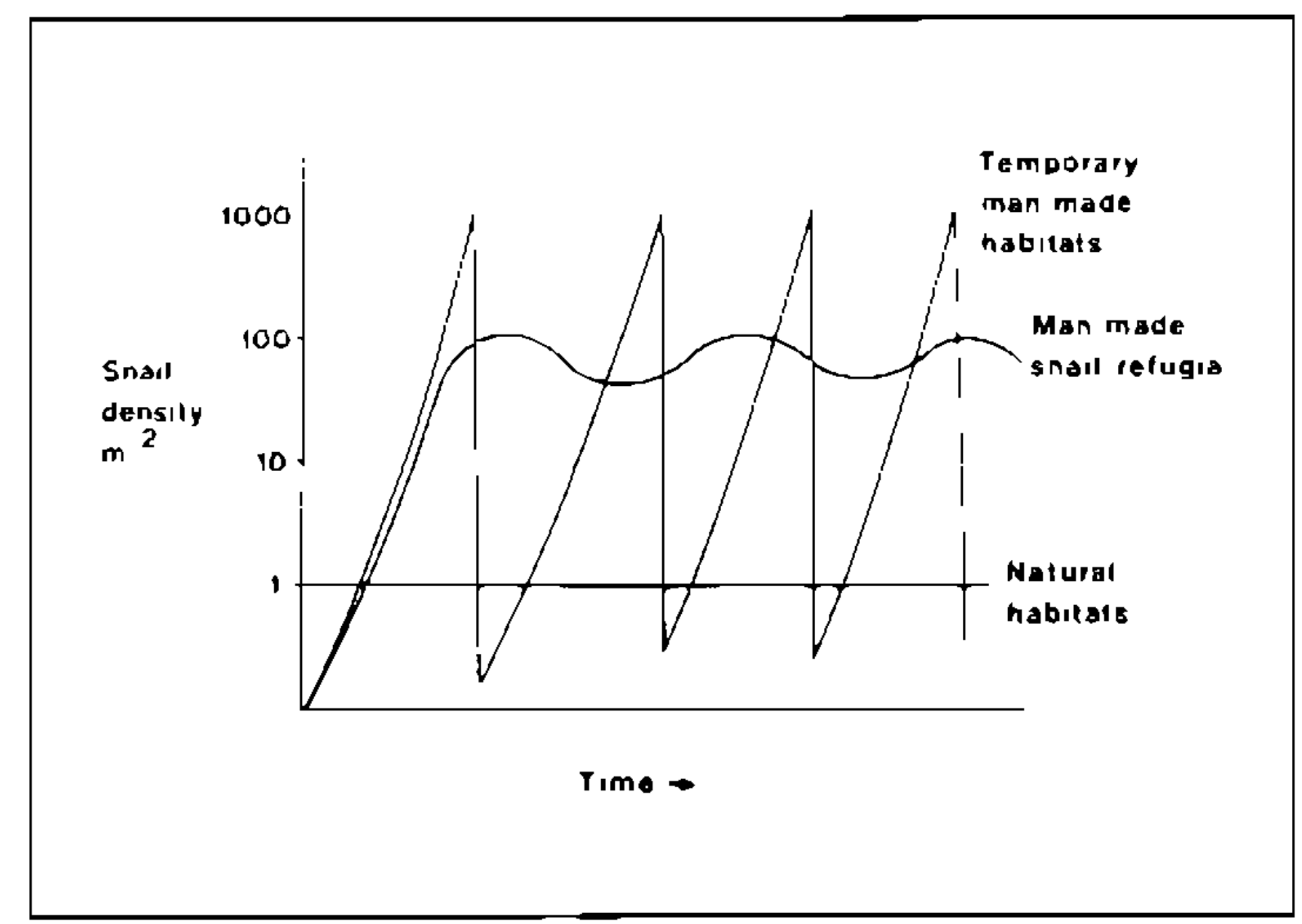

liig. 3: diagram of controlled release formulations.

In the third generation CRF systems advocated by Thomas et al. (1980) (Fig. 3) it was cnvisaged that the CRF would release specific attractants, arrestants and phagostimulants to attract the snails and induce them to ingest the matrix. The latter would then release a molluscicide into the snails' gut. Propanoic or butanoic acids and maltose have bcen identified as attractants and phagostimulants respectively for Biomphalaria glabrata (Thomas et al., 1983, 1986) and it has been demonstrated that crosslinked protein microcapsules containing these are preferentially selected by $B$. glabrata in simulated natural habitats. The next step in producing this "environmental antibody" is the development of a matrix capable of releasing butanoate and maltose into the environment and a toxicant, such as a potent plant molluscicide in pure form or $\mathrm{Cu}(11)$ into the gut of the target snails.

d) Bioengineering approaches - These can be divided into density legislative and density governing methods. It is envisaged that in the former case the measures would exclude the snails, whereas in the latter they would only aim to keep the snail numbers down to acceptably low levels.

\section{- Density legislative measures}

\section{Examples of density legislative measures:}

1. Drainage to exclude water bodies.

2. Increased flow ratcs.

3. Maintenance of high lethal temperatures by lowering water, level and cxposure to sun. 
4. Lowering oxygen levels by eutrophication - e.g. fish pond construction.

Density legislative measures are clearly preferable, as they would exclude snails but are not always practical (McMullen, 1962).

\section{-- Density governing measures}

Although the snail hosts have many natural enemies, including pathogens, predators and parasites (Michelson. 1957) which have potential in control (Nassi et al., 1979; McCullough, 1981) there is now a general consensus that competitor snail species such as Marisa cornuarietis, Helisoma duryi, Melanoides tuberculata, and Thiara sp. hold more promise (McCullough, 1981). There is now a considerable amount of empirical evidence that these snails, with the exception of $H$. duryi, might be successful in controlling the target snails under certain environmental conditions (Jobin et al., 1977; Jordan et al., 1980; Jordan, 1985).

Nevertheless too much optimism that the introduction of these species into the habitats of the snail hosts can provide the final solution to the problem is not justified. There is a need for caution because the target and biocontrol snails have different niches. As a result their distributional patterns will not overlap completely in the heterogenous environment where they live and they could therefore co-exist in the same water bodies (Thomas \& Tait, 1984).

It is therefore necessary to adopt a more holistic approach and to formulate hypotheses regarding which environmental factors might be perturbed to favour the biocontrol molluses and disadvantage the snail hosts. As was the case with the strategies for the control of schistosomiasis, it is intuitively obvious that it is more likely that success will be achieved by subjecting the systems to more than one perturbation at the same time.

One vitally important component of the pulmonate snails environment is macrophytic vegetation. There is evidence that pulmonate snails have co-evolved with aquatic angiosperms since the Cretaceous epoch (Thomas, 1987) and that the various components of modular systems (Fig. 4) consisting of macrophytes, pulmonate snails, epiphytic bacteria and algae, which are linked by six subsets. have strong mutualistic inter-relationships (Thomas et al., 1986). In view of these considerations it would be predicted that removal of macrophytes would be followed by decline in snail populations, although they might still survive on certain kinds of sediment, albeit in smaller numbers. The system consisting of bottom dwelling snails, epilithic bacteria, algae, and the sedimentary particles can be considered as Module type (1), (Fig. 4) which is much earlier from the evolutionary viewpoint than Module type (II). In such a system it is possible that the snail hosts could be excluded by competitor molluscs, such as prosobranchs (e. g. Melanoides or Thiara) or bivalves which utilize the detritus and epilithic micro-organisms efficiently and have the attributes of ' $K$ ' species.

In the light of the above information, some of the possible perturbations which could be used to exclude the snail hosts from lentic or lotic habitats are outlined below.

Possible measures to exclude snails hosts from lentic habitats (see Thomas \& Tait, 1984):

1. Prevention of immigration of macrophytes (e. g. Pistia) and associated snail fauna during the wet season. This could be achieved by using ground water or by installing barriers.

2. Control of subaquatic plants by domestic animals.

3. Encouraging wading birds to utilize food resources such as snails in the draw-down area.

4. Control of floating plants by making optimal use of wind energy (e. g. by making the longitudinal axis of the lake in the same direction as the prevailing wind and having a gradually shelving shoreline at the interface between land and water (Thomas \& Compston, 1980).

5. Control of submerged rooting plants by making water level deep over most of the lake surface and by deploying indigenous herbivorous fish (such as Tilapia zilli) or prosobranch snails such as Marisa cornuarietis or Pila sp.

6. After achieving (5) the lentic system could be used as a high yielding, plankton $\rightarrow$ herbivorous fish $\rightarrow$ carnivorous fish, system.

7. Control of snail hosts in marginal areas by introduction of molluscs or crustacea that could compete successfully for detritus and epilithic organisms. 


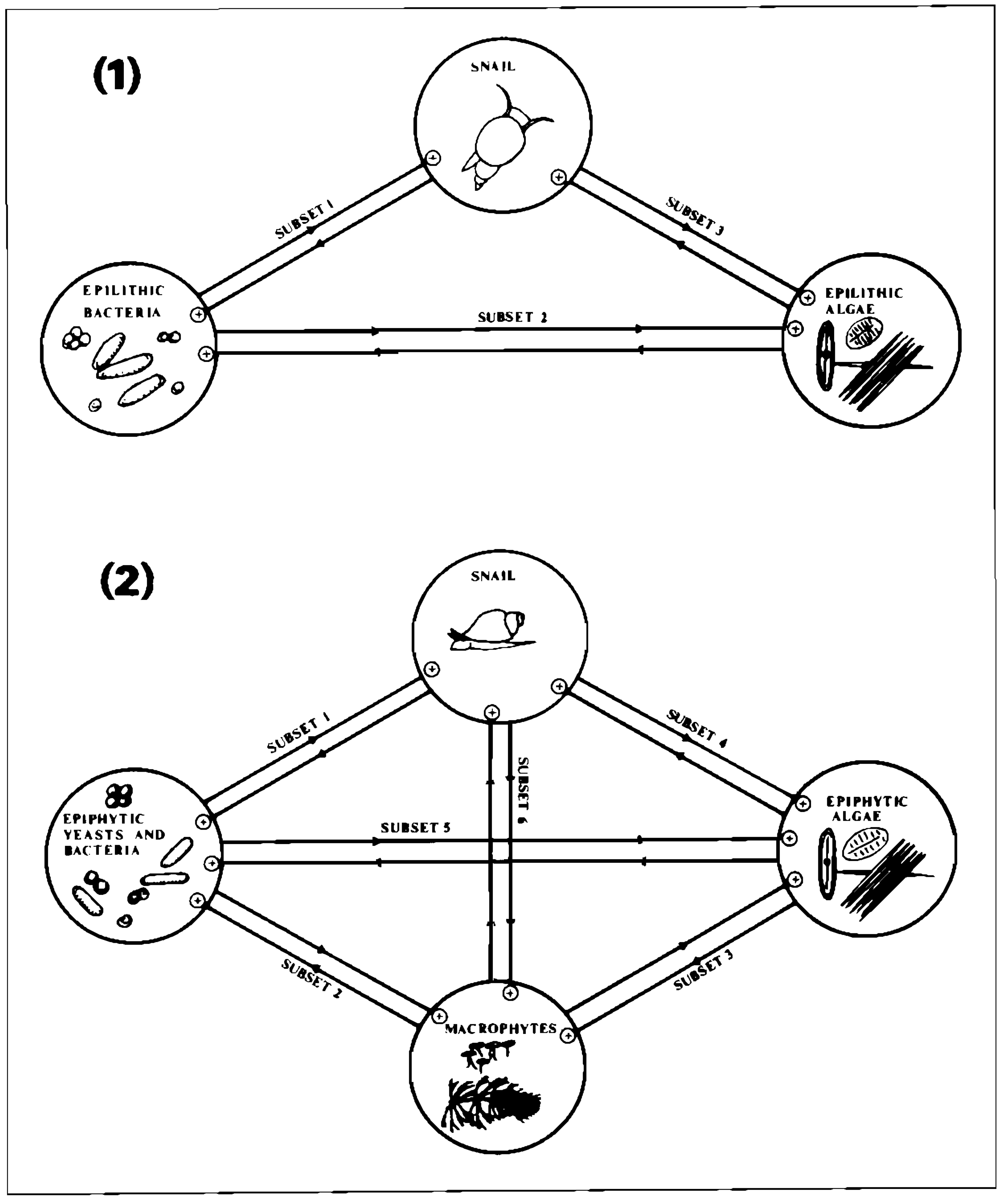

Fig. 4 : diagramatic representation of modulc types I and II.

Possible measures for the exclusion of the snail hosts from lotic habitats:

1. Judicious drainage of refugia, such as marshy headwater spring areas where dense, stable populations of snail hosts may occur.

2. Replacement of encroaching marginal vegetation with strongly competitive, nonencroaching, plant species c. g. Paspalum notatum.
3. Dredging and straightening of river courses to exclude macrophyte beds.

4. Introduction of Melanoides, Thiara or other molluscs well-adapted to live in eroding substrates.

Carefully planned and executed studies, involving interdisciplinary teams of biologists are needed to test the above hypotheses. The 
approach should not be trivialized as ecosystems are very complex. When completed the research should be published in the form of thoroughly evaluated and documented case studies. These could be used as the basis for development of management policies for such water bodies, which would be aimed at the prevention of disease transmission, flooding and drought on one hand, and increased fish production and enhancing the aesthetic appeal of the environment on the other. The case studies could also be used to construct educational programmes for schools, technical colleges, universities as well as those involved in disease prevention (e. g. doctors and nurses in the primary health care field).

\section{CONCLUSIONS}

1. The control of schistosomiasis, in common with the majority of other water related diseases, has proved to be a particularly intractable problem.

2. As no single control strategy has proved effective on its own there is a general consensus that an integrated approach, involving the application of several measures simultaneously, is needed to conquer this disease.

3. These must clearly include chemotherapy (as a curative measure directed preferably at all infected people, or only at those with heavy worm burdens, to reduce morbidity, when resources to fight the disease are limited).

4. However, prevention is preferable to cure and as a result more attention must be paid to the implementation and improvement of preventive measures such as provision of latrines, clean water and snail control. The later is particularly important for those sections of the human population who are obliged to make contact with infected natural or artificial water bodies in connection with their work or for recreational purposes (i. e. fishermen, farmers and children). The problem of snail control must be seen within the ecological context and the needs and aspirations of the people.

5. The production of a vaccine as a preventive measure, must be regarded as an extremely difficult and expensive long term objective, with no guarantee of success.
6. Due to problems inherent in the use of synthetic or natural molluscicides two basically different strategic approaches are advocated (A) The development of an environmental "antibody" based on natural products, which would be designed to remove the target snails selectively in a cost-effective and ecologically acceptable manner. (B) The use of bioengineering perturbations applicable to both lentic and lotic habitats, either to exclude or regulate the snail hosts at acceptably low levels.

7. Both of these approaches require the deployment of integrated interdisciplinary teams. In the case of (A) above, a team should include biologists with experience in whole animal behaviour, toxicology, molluscan physiology and biochemistry as well as formulation chemists. (B) above, on the other hand should include freshwater biologists with a knowledge of molluscan ecology and physiology, plant and fish ecologists, chemists and engineers.

8. The types of lentic and lotic ecosystems requiring investigation are both complex and variable. As a result the research required to evaluate the possible effects of perturbations (some of which are outlined in the present paper) must not be trivialized. It will be necessary to adopt a rigorous, experimental approach to test various hypotheses and to build up a research base founded on weel documented, published case studies.

9. The information gained could be used to develop ecologically based management strategies to achieve many other objectives which would benefit the people (e. g. weed control, flood prevention, fish and bivalve farming, control of insect disease vectors) as well as schistosomiasis control. Great care is required in the implementation of management policies. Attention to detail and a well informed leadership can make the difference between success and failure.

10. The research base could also be used to construct educational programmes aimed at students and employees in educational institutes (schools, technical colleges and universities) as well as those involved in primary health care (doctors and nurses) and in agriculture and water resource development projects (including those financed by aid programmes). 
11. The strategic approaches being advocated straddle two major research domains, namely medicine and food production. The current philosophies of these two areas are expounded by spokesmen from two massive international bureaucracies namely WHO and FAO respectively. Unfortunately the allocation of dwindling resources for research in the medical field has always been strongly biased towards those projects concerned with the adult parasite (chemotherapy and vaccine production) rather than with more ecologically orientated approaches involving a multiplicity of environmental perturbations. On the other hand FAO, who might be expected to have expertise in the latter area, feel the problem is one for the medical fraternity.

12. It is recommended that the necessary steps should be taken through national or international agencies (such as WHO. FAO or UNDP/World Bank) to make it possible to develop the kind of structure and financial support which would make it possible to undertake the kind of interdisciplinary research advocated above.

\section{ACKNOWLEDGEMLNTS}

My thanks are due to the Organizing Committee of the International Symposium on Schistosomiasis held in Rio de Janeiro, Oct. 1987, and also to my friends in the Institute of Oswaldo Cruz, particularly Dr O. S. Pieri, for making the presentation of this paper possible.

\section{REFERENCES}

BRUCE, J. I., 1987. Schistosome drug resistance. Abstract No. 150. Intern. Symp, on Schistosomiasis. Fundação Oswaldo Cruz, Rio de Janeiro, Oct., 1987.

CHANDIWANA, S. K. \& NDAMBA, J., 1987. Field and laboratory evaluation of controlled release copper glass as a molluscicide in snail control. Abstract No. 30. Intern. Symp. on Schistosomiasis. Fundaçāo Oswaldo Cruz, Rio de Janciro, Oct., 1987.

DAMION, R. T.. 1987. The exploitation of host immune responses by parasites. J. Parasit., 73: $1-13$.

DRAKE, C. F. \& GRAHAM, M., 1976. Inorganic glasses as slow release herbicides and fungicides. Spec. Publ. No. 29 Chem. Soc. London.

DUNNE, D. W.; IUULFORD, A. J. C.; BUTTERWORTH, A. I:. KOECH, D. \& OLMA, J. H., 1987. Human antibody responses to Schistosoma mansoni: docs antigen dirccted isotype restriction result in the production of blocking antibodies.
Intern. Symp. on Schistosomiasis. Fundaçāo Oswaldo Cruz, Rio de Janeiro, Cet., 1987.

HAIRSTON, H. G., 1971. Review of Human Schistosomiasis by P. Jordan \& G. Webbe. Am. J. Trop. Med. Hyg., 20: 164-165.

HOFFMAN Jr., D. B.; LEHMA ${ }^{N} \mathrm{Jr}_{\text {., }}$ J. S.; SCOTT, V. C.; WARREN, K. S. \& WEBBE, G., 1982. Control of Schistosomiasis* report of a workshop. Amer. J. Trop. Med. Hyg., 28: 249-259.

JOBIN, W. R.; BROWN, R. A.; VELEZ, S. P. \& FERGUSON, F. F., 1977. Biological control of Biomphalaria glabrata in major reservoirs of Puerto Rico. Am. J. Trop. Med. Hyg., 26: 10181024.

JORDAN, P., 1972. Epidemiology and the control of schistosomiasis. Brit. Med. Bull., 28: 55-59.

JORDAN, P., 1985. Schistosomiasis: the St Lucia project. Cambridge Univ. Press. London.

JORDAN, P.; CHRISTIE, J. D. \& UNRAU, G. O., 1980. Schistosomiasis transmission with particular reference to possible ecological and biological methods of control: a review. Acta Tropica, 37: 95-135.

JORDAN, P. \& WEBBE, G., 1982. Schistosomiasis, epidemiology, treatment and control. Heinemann Mcdical Books. London, $361 \mathrm{p}$.

LFMMA, A.; HFYNEMANN, D. \& KLOOS, H., 1979. Studies of molluscicidal and other propertics of the endod plant Phytolacca dodecandra. Dept. of Epidemiology \& International Health. Univ. of California. San Francisco. California. 522 p.

MACDONALD, G., 1965. The dynamics of helminth infections with spccial reference to schistosomes. Trans. R. Soc. Trop. Med. Hyg., 59:489-506.

MACHADO. P. A., 1982. The Brazilian programme for schistosomiasis control 1975-1979. Amer. J. Trop. Med. Hyg., 31: 76-86.

MACHADO, P. A.; SILVA, J. R.; FAERSTEIN, N. F.; RODRIGUES, R. G,; MAGALHÃES-MACHADO, M. E ; VALINMO, C.; ROSA, P. M. S.; MALDO. NADO, A.; CASTRO-REZENDE, A.; OLIVEIRA, R. M. F.; LENZI, H. L. \& REY, L., 1987. Rodents as biological filters in $S$. mansoni transmission: epidemiological implications to schistosomiasis control. Abstract No. 133. Int. Symp. on Schistosomiasis. Rio de Janeiro. Oct. 1987.

MCCULLOUGH, F. S., 1981. Binlogical control of the snail intermediate hosts of huyman schistosoma spp.: a review of its present status and future propects, Acta Tropica, 38: 5-13.

MCCULLOUGH, F. S. \& MOTT, K. E., 1983. The role of molluscicides in schistosomiasis control. WHO/ $\mathrm{VBC} / 83.879 / \mathrm{WHO} / \mathrm{SCHISTO} / 83 / 72.13 \mathrm{p}$.

MCMULLEN, D. B., 1962. The modification of habitats in the control of bilharziasis, with special reference to water resource developments. In: 'Bilharziasis'. Ciba Foundation Symposium. 382396 (eds. Wolsteholme, G. E. W., O'Connor, M. Little Brown \& Co. Boston.

MICHELSON, F. H., 1957. Studies on the biological control of schistosome bearing snails. Predators and parasites of freshwater molluscs: a review of the literature. Parasitology, 47: 413426.

MODENA, C. M.; BARBOSA, F. S.; COELHO, P. M. Z. \& LIMA, W. S., 1987. The role of cattle in the epidemiology of Schistosoma mansoni. Abstract No. 131. Intern. Symp. on Schistosomiasis. Fundação Oswaldo Cruz, Rio de Janeiro, Oct. 1987. 
MOTT, K. E., 1987a. Plant Molluscicides. UNDP/ World Bank/WHO Special Programme for Research and Training in Tropical Diseases. J. Wiley, Chichester.

MOTT, K. E., 1987b. Operational implications of antischistosomal drug resistance. Abstract 151. Intern. Symp. on Schistosomiasis. Fundação Oswaldo Cruz, Rio de Janeiro, Oct. 1987.

NASSI, H.; POINTIER, J. P. \& GOLVAN, V. J., 1979. Bilan d'un essai de contrôle de Biomphalaria glabrata en Guadeloupe à l'aide d'un trématode stérilisant. Ann. Parasit., 54: 185-192.

SHOEB, H. A. \& EL-CHANY REFAHY, L. B., 1984. The molluscicidal properties of Calendula micrantha (officinalis). Proc. Inst. Malac. Congr. Italy, p. 233-240.

THOMAS, J. D., ASSEFA, B.; COWLEY, C. \& OFOSU-BARKO, J., 1980. Behavioural responses to amino acids and related compounds including propionic acid by adult Biomphalaria glabrata host of Schistosoma mansoni Comp. Biochem. Physiol., 66: 17-27.

THOMAS, J. D. \& COMPSTON, D. G., 1980. A bioengineering approach to the control of aquatic weeds in a tropical lake. In: Weeds and their control in the humid and subhumid tropics. Int. Inst. Trop. Agric. Ibadan, Nigeria. Proc. Series 3 VII (ed. I. O. Akobundu) p. 421.

THOMAS, J. D.; OFUSO-BARKO, J. \& PATIENCE, R. L., 1983. Behavioural responses to carboxylic and amino acids by Biomphalaria glabrata (Say) the snail hosts of Schistosoma mansoni (Sambon) and other freshwater molluscs. Comp. Biochem. Physiol., 75: 57-76.

THOMAS, J. D. \& TAIT, A. I., 1984. Control of the snail hosts of schistosomiasis by environmental manipulation. A field and laboratory appraisal in the Ibadan area of Nigeria. Phil. Trans. $R$. Soc. Lond., B305: 201-253.

THOMAS, J. D.; STERRY P. R.; JONES, H.; GUBALA, M. \& GREALY, B. M., 1986. The chemical ecology of $B$. glabrato (Say): sugars as phagostimulants. Comp. Biochem. Physiol., 83: 461.475 .

THOMAS, J. D.; NWANKO, D. I. \& STERRY, P. R., 1986. The feeding strategies of juvenile and adult $B$. glabrata (Say) under simulated natural conditions and thei relevance to ecological theory and snail control. Proc. R. Soc. Lond., B226: 177-209.

THOMAS, J. D., 1987. An evaluation of the interactions between freshwater pulmonate snail hosts of human schistosomiasis and macrophytes. Phil. Trans. R. Soc. London, B31 5: 75-125.

WARREN, K. S., 1987. Schistosomiasis: past, present and future. Abstract 162. Int. Symp. on schistosomiasis. Fundação Oswaldo Cruz, Rio de Janeiro, Oct., 1987.

WHO, 1980. Epidemiology and control of schistosomiasis. Report of a WHO Expert Committee. Technical Report Ser. 643. WHO. Geneva.

WOR THINGTON, E. B., 1979. Some ecological problems concerning engineering and tropical disease. Progress in Water Technology, 11:5-11. 